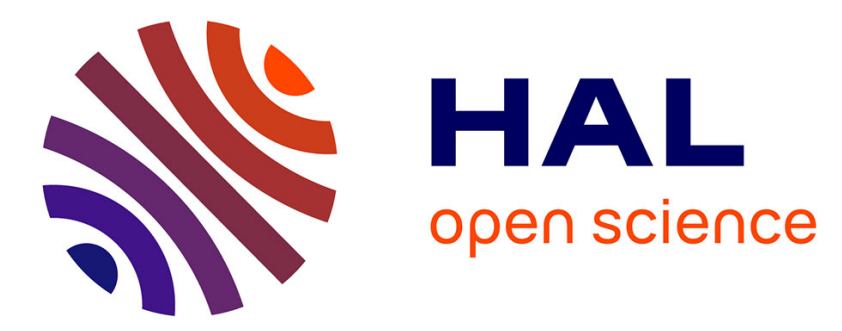

\title{
Learning Letters with the Whole Body: Visuo-Motor versus Visual Teaching in Kindergarten
}

Florence Bara, Nathalie Bonneton-Botté

\section{To cite this version:}

Florence Bara, Nathalie Bonneton-Botté. Learning Letters with the Whole Body: Visuo-Motor versus Visual Teaching in Kindergarten. Perceptual and Motor Skills, 2017, 125 (1), pp.190-207. 10.1177/0031512517742284 . hal-01889090

\section{HAL Id: hal-01889090 https://hal.science/hal-01889090}

Submitted on 5 Oct 2018

HAL is a multi-disciplinary open access archive for the deposit and dissemination of scientific research documents, whether they are published or not. The documents may come from teaching and research institutions in France or abroad, or from public or private research centers.
L'archive ouverte pluridisciplinaire HAL, est destinée au dépôt et à la diffusion de documents scientifiques de niveau recherche, publiés ou non, émanant des établissements d'enseignement et de recherche français ou étrangers, des laboratoires publics ou privés. 
Learning Letters with the Whole Body: Visuo-Motor versus Visual Teaching in Kindergarten Bara, F. (CLLE-LTC, Université Jean-Jaurès, ESPE, Toulouse)

Bonneton-Botté, N. (LP3C, UBO, ESPE)

\begin{abstract}
In early school years, children must learn letters; what constitutes effective teaching is still uncertain. In this study, we assessed the impact of a teacher-implemented visuo-motor intervention program to teach 5-year-olds' cursive letter knowledge. We compared a program in which letters were explored with the arm and whole body, with a typical visual training program. Children were tested before and after the intervention with different measures of letter knowledge. We showed a greater improvement in letter recognition following the visuomotor intervention, compared to the visual intervention. Results were mixed for letter handwriting: higher scores on stroke direction and overall quality, but lower scores on fluency following visuo-motor teaching. We discuss these results in terms of the link between action and perception, the interaction between the different components of letter knowledge, and the link between fine and gross motor development and handwriting.
\end{abstract}

Keywords: letter knowledge, handwriting, motor learning, kindergarten 


\section{Introduction}

Letter knowledge acquisition is an important component of children's literacy development, and it is one of the strongest predictors of later reading and spelling abilities (Hammill, 2004; Pennington \& Lefly, 2001; Schatschneider, Fletcher, Francis, Carlson, \& Foorman, 2004; Shatil, Share, \& Levin, 2000). Letter knowledge refers to four components that interact together and affect the course of literacy acquisition (Foulin, 2005; Puranik, Lonigan, \& Kim, 2011): (i) Letter recognition is the ability to recognize the shape of the letter; (ii) letter naming consists in associating the shape of the letter to her name; (iii) letter sound knowledge requires to find the sound corresponding to the shape or to the name of the letter; (iv) and letter writing is the ability to trace the letter with a pen in accordance with shape and direction. Despite the importance of the latter component for literacy acquisition, Puranik, Al Otaiba, Sidler and Greulich (2014) observed that writing activities are frequently neglected in teaching practice.

Letter recognition making it easier to remember and discriminate between the letters' visual features, in turn enhances word recognition (Ehri \& Sweet, 1991). As letter names and letter sounds are strongly linked, instruction in letter names supports letter-sound learning, and boosts the learning of phonetic spelling (Evans, Bell, Shaw, Moretti, \& Page, 2006; Justice, Pence, Bowles, \& Wiggins, 2006; Piasta, Purpura, \& Wagner, 2010; Treiman, Kessler, \& Bourassa, 2001). Letter writing is a complementary, interacting skill (Molfese, Beswick, Molnar, \& Jacobi-Vessels, 2006), and as letter writing requires access to the visual representation of the letters stored in memory, in order to construct the motor program, visual letter recognition is a necessary stage of its acquisition as well. Conversely, writing practice influences letter recognition, because writing movements are involved in letter-shape memorization (Bara, Gentaz, \& Colé, 2007; Bara, Gentaz, Colé, \& Sprenger-Charolles, 2004; 
Longcamp, Zerbato-Poudou, \& Velay, 2005).

When learning involves both perceptual and motor systems as, for example, when acquiring letter knowledge, there is an interaction between perception and action. This interaction has been demonstrated in rapidly growing research in the field of grounded or embodied cognition (Barsalou, 2008; Kiefer \& Trumpp, 2012). This research has shown that when people perceive objects that can be manipulated, they experience mental stimulations or representations of actions that could be performed on them. These motor simulations speed up the visual recognition of the objects and even reading their names (Chao \& Martin, 2000; Helbig, Graf, \& Kiefer, 2006; Martin, 2007; Pulvermüller, 2005). Visual representations of letters are linked to motor representations through learning and practicing handwriting, and neuroimaging research suggests that even seemingly passive visual letter perception recruits motor systems that are usually dedicated to executing handwriting movements (James \& Atwood, 2009; James \& Gauthier, 2006; Longcamp, Anton, Roth, \& Velay, 2003). Related to this perception and motor interaction process, some studies in young children have shown that overt, rather than just passive, motor action enhances letter perception. For example, Longcamp and colleagues (2005) showed that handwriting practice improves letter recognition more than typing practice does, while Labat, Ecalle, and Magnan (2010) showed that graphomotor training improves letter-sound knowledge and spelling. Bara and colleagues (Bara, Gentaz, \& Colé, 2007; Bara, Gentaz, Colé, \& Sprenger-Charolles, 2004) found that haptic exploration of letters leads to a higher rate of improvement in kindergarten children's letter recognition, letter handwriting and pseudoword decoding than does visual exploration.

To be properly mastered, formal pencil-and-paper writing depends upon an accurate visual representation of the letters, a degree of coordination between visual perception and finger movements (Daly, Kelley, \& Krauss, 2003), and sufficiently developed fine motor skills (Cornhill \& Case-Smith, 1996) to execute a graphic representation of what was first 
perceived. Studies attempting to clarify the impact of fine motor skills on handwriting, showed that slow handwriters, from 8 to 13 year-olds were less efficient in upper limb speed and dexterity than were normal speed handwriters (Tseng \& Chow, 2000; van Hoorn, Maathuis, Peters \& Hadders-Hagra, 2010). Impaired handwriting, which is frequently associated with developmental coordination disorder, has in particular been closely linked to fine manipulative disability and to coordination problems (Rosenblum, 2015). Fine motor skills are needed to hold a pencil and use it with accuracy in order to perform precise and refined movements (Amundson \& Weil, 2001). However, children in the first years of school display varying levels of fine motor skills, and at five years of age, $20 \%$ of children continue to use primitive or transitional grips (movement controlled by extrinsic muscles) (Schneck \& Henderson, 1990). Beyond the role of fine motor skills, the whole motor maturity and the vestibular system could affect writing since there is for example evidence that links asymmetrical tonic neck reflex to reading and writing skills (McPhillips, Hepper \& Mulhem, 2000; Niklasson, 2012).

Approaches to letter knowledge instruction vary greatly, and what constitutes effective and appropriate instruction is still the focus of much research (Piasta \& Wagner, 2010). To be efficient, intervention needs to include both handwriting practice and direct instruction in letter knowledge (Hoy, Egan, \& Feder, 2011). Sensorimotor interventions that do not specifically focus on letter teaching have not proved efficient, and research results about directly transfering perceptual, motor or kinesthetic skills to handwriting are still amidst debate (Blank et al., 2012 ). Bara et al. (2004 ; 2007) obtained great improvement on letter knowledge and reading with their multisensory intervention, when haptic exploration of letters was combined with phonological exercises and when specific instruction was given in how to explore the letters.

Our study attempted to advance this research by investigating a novel kindergarten 
level multisensory teaching intervention for letter knowledge. We sought to assess the impact of teaching alphabet letters through gross motor movements by asking pupils to produce letters with the arm or the whole body without using a pencil. To our knowledge, even if it is sometimes a practice used in schools, the effect of this approach has never been tested. Since handwriting learning is closely related to fine motor development that is ill suited for five year olds, it would be worthwhile to find gross motor, rather than fine motor, ways of helping young children or children with slower than normal motor development acquire letter knowledge and related handwriting proficiency. We take the view that it is better to encourage children with poor fine motor skills to engage in related activities that support letter perception development than to force them to write with a pencil before they are ready. The benefits of learning letters through low-amplitude hand movements have already been demonstrated (Bara et al., 2004; 2007; 2011). We assumed that the movement needs to match the letter shapes as with handwriting, but that different kinds of motor experience, with different effectors, can efficiently promote alphabet letter acquisition for very young children. As gross motor development occurs earlier than fine motor development (Cratty, 1979), gross motor movements should be helpful for young children learning letters even when fine motor movements required for handwriting are still not available to them. Thus, we compared the effects of two different training programs (visuo-motor and more typical visual) on letter knowledge acquisition. These two programs both focused on direct letter instruction (letter name, letter shape, way of tracing a letter), but differed in the way letters were explored. We predicted that the visuo-motor training program would be more efficient than the visual program. We assume this intervention would enhance the visual representation of the letters which, in turn, would impact handwriting. We expect an improvement in handwriting quality and fluency, and a decrease in the number of pauses during the execution of the movement. 


\section{Method}

\section{Participants}

Participants were 72 kindergarten pupils (31 girls and 41 boys) with a mean age of 5 years and 4 months when the training programs began. All of them were in their final year of kindergarten in France (kindergarten lasts 3 years). They were normally developing children recruited from five different classes in three schools from a middle sized city. We obtained written parental consent for each child. Two of the schools were attended by children from a middle socio- economic status, while the third was located in an education priority area (most of the children came from low- to middle-class families). The training programs were implemented by the children's teachers. All teachers were school employees, and none of them had been affiliated with a university research project prior to the present study. The instructional programs were implemented by the teachers in an ecological setting so as to strengthen the link between innovative research and typical practitioner activities. It is rare for teachers to implement research programs themselves in intervention studies, even though two meta-analyses (Ehri et al., 2001; Piasta \& Wagner, 2010) have shown that they are just as effective as researchers at teaching phonological awareness and letter knowledge. Typically, when researchers do the teaching, their involvement is limited to the duration of the research, whereas teachers may internalize the educational goals and continue using the program for the benefit of future pupils. Before the interventions, the teachers participated in two 1-hour theoretical and methodological workshops where information was given concerning handwriting learning and teaching, cognitive processes in handwriting, experimental methodology, and how to follow an experimental protocol. The eight teachers involved had 5-12 years of experience.

\section{Material}


For the letter knowledge tasks, the letters were printed in black on a white sheet of paper. All letters were in cursive script, which is the official handwriting script in French schools. For letter name and letter sound identification, one letter was printed in the middle of small card $(6 \times 6 \mathrm{~cm})$; for letter recognition, 10 letters were printed on A4 white sheet of paper.

The handwriting productions were collected on a white sheet of paper $(12 \times 20 \mathrm{~cm})$ fixed on a tablet. A Wacom Intuos 2 graphic tablet, connected to a computer was used to record the children's handwriting movements. The letters were handwritten with an Intuos inking pen.

The Rey-Osterrieth Complex Figure was used to match the children in the two training programs. This is a neuropsychological measure commonly used to assess visuospatial processing, planning, visuomotor integration and memory (Baron, 2000). It has been used with normally developing children as well as with children with learning disabilities (Beebe, Ris, Brown, \& Dietrich, 2004 ; Kirkwood et al., 2001). The children had to copy the figure. The number of components correctly copied was rated.

\section{Procedure}

In each class, the pupils were assigned to one of the two training programs: visuo-motor or visual. Before the beginning of the interventions, the pupils' initial level was assessed by means of individual tests that allowed to match them. Three tests were used: letter-name knowledge, phonological awareness (matching eight words that started or finished with the same sound), and Rey figure test. No differences were found between the two groups of pupils (Student $t$ tests, all $p \mathrm{~s}>.25$ ). The pupils' initial level is indicated in Table 1 . 
The training programs were held by the teachers once a week in the afternoon, between regular daily activities. Before the programs started, the pupils had not yet begun to learn how to write letters in cursive script. In France, before entering elementary school, children master the movements required to write, learn the strokes that form the letters, and start writing cursive letters and words (French school syllabus, 2015). For the purpose of the present study, they only learned cursive handwriting during the training sessions and teachers gave no other supplementary handwriting instruction. The pupils, divided into groups of 6-10, underwent a 45-minute session in which two letters were successively learnt. As it was proved to be efficient we chose to work with small groups (Connor, Morrisson, \& Slominski, 2006). All the children completed six sessions (two letters in each session) over a period of six weeks. The 12 letters used for the training sessions were -a-, -i-, -r-, -n-, -t-, -v-, -b-, -1-, $\mathrm{d}-,-\mathrm{m}-$, , - -, and -f-. The letters and their order of presentation were chosen according to their frequency in the French language and because they represented different types of letters (vowel, stop consonant, nasal consonant, voiceless consonant and voiced consonant). To control for a possible teacher effect, each teacher implemented both the visual and the visuomotor programs. Two sessions, one in each training program, were videotaped and analyzed, and two other sessions (at the beginning and in the middle of the training period) were observed by a researcher who then coached teachers, all with the intent of insuring that teachers adhered closely to the intended programs.

Letter knowledge tests (letter recognition, letter-name knowledge and letter handwriting) were administered individually (taking over 20 minutes each per child) by an experimenter in a quiet room at the child's school both two weeks before and two weeks after the interventions.

Pre- and Post-tests.

Letter recognition. The experimenter said the name of a letter, and the child had to 
identify it among 10 other letters by pointing to it with his finger. The nine other letters were visually similar to the target letter. Each correct answer was scored 1 . Only the 12 letters used in the training sessions were tested in this task. These letters were presented in random order, with each of the 12 letters presented twice (yielding a possible total score of 24).

Letter-name knowledge. Each of the 12 letters was written on an individual card and presented in the same random order to each child. The child was asked to give the name of each letter (maximum score $=12)$.

Letter handwriting under dictation. Each child had to write the 12 letters on a white sheet of paper when the experimenter said their names. The number of correct handwritten letters was counted (maximum score $=12$ ).

Letter copying. Each child was asked to copy the 12 letters one by one. A model of the letter was printed in the top left hand corner. The stroke order was rated, with one point being awarded for each letter written with the conventional stroke direction (maximum score $=12$ ). An overall assessment of letter quality was performed by two independent raters (elementary school teachers) who were blind to the aim of the study and the learning conditions. They had to judge the overall quality of each letter and give a mark between 0 and 5 ( 0 being an unrecognizable letter, and 5 being a letter considered to be perfectly handwritten for a child of that age). Interrater agreement was high (Cohen's weighted kappa coefficient, $\kappa=.87)$. We applied a combined approach to handwriting evaluation that took advantage of both human and digitizing tools, and which allowed us to gain a comprehensive view of the children's letter handwriting (Rosenblum, Weiss, \& Parush, 2003). Data acquisition and analysis were performed with Ductus software (Guinet \& Kandel, 2010). Different data about movement proficiency (velocity, fluency, number and duration of pauses) were collected and analysed. The copying task always followed the letter handwriting under dictation task. 
Visual Training Sessions.

Visual Exploration. Each letter was displayed on the board in front of the pupils. The teacher asked them to draw the letter with their eyes, focusing on its shape, lines and curves. The stroke direction was indicated by arrows on the letters.

Visual Discrimination. Eight letters were displayed on the board (five copies of the target letter and three distractor letters). Each pupil had to identify each of the target letters in turn.

Visual Recognition of Letters inside Words. Eleven words were displayed on the board (eight words containing one or two target letters). The words were not read out loud. Each child had to identify each of the target letters in turn.

\section{Visuo-motor Training Sessions.}

Exploration with the Arm. Back turned and in a squatting position, the teacher drew the letter in the air with his/her arm. The pupils were required to repeat this action, first with their eyes open, then with their eyes shut. In the second part of the exploration process, we removed the visual feedback so that the pupils could concentrate on the proprioceptive information to build their representation of the letter.

Exploration with the Body. The letter was drawn on the ground and each pupil walked along its outline. They performed this exercise first with their eyes open, then with their eyes shut, guided by another pupil. In the second part of the exploration process, we removed the visual feedback so that the children could concentrate on the proprioceptive information.

Each visuo-motor and visual training session started by giving the name and the sound of the letter and ended with letter-recognition and letter-handwriting tasks. The pupils were shown different letters (targets and distractors) and had to cross out all the target letters. They then had to handwrite the two letters from memory on a white sheet of paper, trying to follow 
the conventional stroke order. They received feedback about their production from the teacher. It should be noted that the type of exercises in the two training programs were not completely equivalent. As we wanted to equalize in each program the overall time allocated to each session, we had to use a variety of exercises in the visual training program. It was impossible to ask 5-year-olds to keep on looking at a letter for 15 minutes, which is the time it took for them to explore the same letter with their body. We therefore included discrimination and recognition exercises in the visual training program to make the sessions more attractive for the children. The visual training sessions and the visuo-motor training sessions lasted exactly the same time.

\section{Results}

To compare the impact of the training programs between the two test times, we calculated a 2 (training program) x 2 (time) analysis of variance (ANOVA) for each measure. Training program (visuo-motor vs. visual) was the between-participants factor, and time (pretest vs. post-test) the within-participants factor.

\section{Letter Knowledge Measures}

Please see Table 2 for the results of several of the Letter Knowledge dependent measures.

\section{[Insert Table 2 about here.]}

Letter recognition. The main effect of time of testing, $F(1,70)=185 ; p=.00$, and the interaction between time and training program, $F(1,70)=5.11 ; p=.027$, were both significant, but the main effect of training program, $F(1,70)=0.07 ; p=.78$, was not significant. On average, the students improved more their score in letter recognition with the visuo-motor training program than with the visual program. 
Letter-name knowledge. The main effect of time of testing was significant, $F(1,70)=$ $80.61 ; p=.00$, but neither the main effect of training program, $F(1,70)=0.19 ; p=.66$, nor the interaction was significant, $F(1,70)=0.9 ; p=.75$. The number of correctly named letters increased between the pre- and post-tests in both training programs.

Letter writing under dictation. The main effect of time of testing was significant, $F(1$, $70)=47.51 ; p=.00$, but neither the main effect of training program, $F(1,70)=0.06 ; p=.80$, nor the interaction was significant, $F(1,70)=0.93 ; p=.34$. The number of written letters improved between the pre- and post-tests in both training programs.

\section{Letter Handwriting (Copying Task)}

The results for Letter Handwriting are set out in Tables 3 and 4.

[Insert Tables 3 and 4 about here.]

Overall Legibility (Quality Score). The main effect of time of testing, $F(1,70)=63.15$; $p=.00$, and the interaction between time and training program, $F(1,70)=8.65 ; p=.004$, were significant, but, the main effect of training program was not significant, $F(1,70)=.47$; $p=.49$. Mean quality scores improved more after the visuo-motor training program $(M=$ 3.28) than after the visual program $(M=3.01)$.

\section{Kinematic Measures.}

Stroke Direction. The main effect of time of testing, $F(1,70)=130.94 ; p=.00$, and the interaction of time of testing and training program, $F(1,70)=13.93 ; p=.00$, were significant, but the main effect of training program was not significant, $F(1,70)=3.05 ; p=.07$. The improvement between pre-and post-tests in handwriting direction was greater in the visuomotor training program than in the visual program.

Mean Number of Pauses. The main effect of time of testing, $F(1,70)=61.82 ; p=.00$, was significant, but neither the main effect of training program, $F(1,70)=2.49 ; p=.12$, nor 
the interaction, $F(1,70)=2.15 ; p=.15$, was significant. The mean number of pauses decreased between the pre- and post-tests in both training programs.

Mean Duration of Pauses. The main effect of time of testing, $F(1,70)=40.69 ; p=.00$, was significant, but neither the main effect of training program, $F(1,70)=0.00 ; p=.97$, nor the interaction, $F(1,70)=1.63 ; p=.20$, was significant. The duration of the pauses decreased between the pre- and post-tests in both training programs.

Mean Velocity. The main effect of time of testing, $F(1,70)=9.95 ; p=.002$, was significant, but neither the main effect of training program, $F(1,70)=3.12 ; p=.08$, nor the interaction was significant, $F(1,70)=3.56 ; p=.06$. Velocity increased between the pre- and post-tests in both training programs.

Fluency. The main effects of training program, $F(1,70)=4.96 ; p=.03$, and time, $F(1$, $70)=7.71 ; p=.007$, and the interaction, $F(1,70)=8.09 ; p=.006$, were all significant. The pupils' handwriting fluency improved more in the visuo-motor training program than in the visual program.

\section{Discussion}

The main finding of the study was that the letter recognition rate improved more following the visuo-motor training program than the visual training program. Like haptic exploration (Gentaz et al., 2009) and handwriting (Longcamp et al., 2005; Labat, Ecalle, \& Magnan, 2010), gross motor exploration of the letters had a positive impact on their recognition. This is an interesting finding, as the visual recognition process was emphasised more in the visual training program than in the visuo-motor program. During the visual training sessions, pupils had to pay attention to the shapes of the letters, and were trained to recognize the target letters and distinguish them from similar ones. The task used in the preand post-tests to assess letter recognition was quite similar to the exercises pupils performed. 
Despite this task similarity and more intensive visual recognition training in the visual training program, pupils in this learning condition performed more poorly on letter recognition than did their counterparts in the visuo-motor training program. This effect can be interpreted in light of the embodied theory of learning who highlight strong relationship between the visual and the motor system in reading and writing processes (James \& Atwood, 2009; James \& Gauthier, 2006; Longcamp, Anton, Roth, \& Velay, 2003). The motor gesture reinforces the visual representation of letters. The activation of multicomponent traces then favour the memorization process both for encoding and recall. It is interesting that the motor act associated with visual letter learning may not need to be specifically a handwriting movement or performed solely by the hand but, rather, may involve a larger movement, with arm or with a leg movement along the shape.

Difficulties in letter handwriting can arise from difficulties with visual perception and/or motor control. Perceptual abilities are linked to handwriting quality, whereas motor skills are linked to the quality of the movement that produces the letter trajectory, and thus to the kinematic properties of handwriting (Bara \& Gentaz, 2011). If we assume that handwriting quality depends on the quality of visual representations in memory, it is easy to understand why the overall quality of letter handwriting was higher in the visuo-motor training program than in the visual training program. However, it is surprising not to find a difference in the number of letters written under dictation over the two training programs. From our point of view, the handwriting task might not have been sufficiently automated in young children (as evidenced by the fluency index) for improved letter recognition to positively impact performance in the number of letters written under dictation.

Regarding the kinematic measures, the visuo-motor training program only had a positive effect on stroke direction. This effect can be explained by the different amount of practice during the two training programs. Stroke direction was practiced a great deal in the 
visuo-motor program, as the pupils had to draw each letter with their arm and walk along its outline, following the conventional stroke order. In the visual intervention, by contrast, stroke direction assistance was only provided in the form of arrows on the letters. The pupils were able to visualize the stroke direction, but did not practice it. It is interesting to note that a gross motor movement can transfer to a fine motor movement with the hand. To our knowledge, no such transfer has been studied in early learning, even though adults have been shown to produce the same, invariant written output with different effectors (preferred and nonpreferred hand, mouth, foot, etc.; Raibert, 1977).

An unexpected result of this study was that handwriting fluency improved more following the visual training program than visuo-motor training program. Letter handwriting fluency is usually associated with the ease with which the letter strokes can be drawn and linked together, and with the amount of sensory feedback used to control the movement (Danna \& Velay, 2015). Five year-old children experience difficulty in controlling the speed of writing while integrating visual feedback (Chartrel \& Vinter, 2008). With regard to their higher performance in legibility and stroke direction under visuo-motor learning, a possible explanation is that students were engaged in a closed loop feedback control strategy. In other words, because of limited working memory capacity and the cognitive load generated by the handwriting task (Kellogg, 2001; Olive, 2012), learning letter shapes was favoured over learning motor fluency. This assumption questions the time course for teaching the different components of handwriting. Another explanation linked with embodied cognition theory might be that children after the visuo-motor training were more quite capable to evoke the mental imagery of the movement while writing, performing that way a more time-consuming task than children who learnt the letters visually.

The absence of a difference in the number of pen lifts was also unexpected. Pauses in the movement are usually associated with the need to look at the model while producing the 
graphic trace, and thus might increase with an incomplete visual representation of the letter in memory (Lambert \& Esperet, 2002). However, examining pupils' pen lifts may not be sufficient to understand what they do when they pause if not associated with eye movements measure (Alamargot, Chesnet, Dansac, \& Ros, 2006). Moreover, as shown by Paz-Villagran, Danna, and Velay (2014), pen stops - when the pen stops moving but remains in contact with the paper- were better than pen lifts for differentiating handwriting fluency skills of normally developing children and those with dysgraphia.

The present study provides support for a visuo-motor intervention to promote such specific components of letter learning as improving letter recognition and improving two aspects of letter writing (stroke direction and overall quality), while handwriting speed and fluency improved more with a visual instructional method. The visuo-motor intervention was successfully implemented by kindergarten teachers in regular classrooms with program fidelity verified by videotape analysis and classroom observations. As many children experience difficulties in fine motor skills and handwriting, and especially those with developmental coordination disorder (Rosenblum, 2015), it is interesting to show that handwriting can be developed through gross motor movements with no necessity for holding a pencil. From our point of view it opens novel ways for remediation and prevention of handwriting difficulties.

Several study limitations need to be pointed out. For a start, our study focused on cursive handwriting, the official script in France, which may hinder the generalization of our results. Indeed, cursive script and printed letters differ in shape, the importance of direction, and motor movement (Schwellnus, Cameron, \& Carnahan, 2012). Second, the visuo-motor training program did not allow us to disentangle the effects of motor arm and body movements, and these may be differentially important.

Letter knowledge and, in turn, literacy skills depend upon several interacting skills. 
Despite a growing number of research studies, it is still difficult to understand precisely how motor action can improve letter learning. A deeper investigation of the motor influence on visual perception of letters during learning processes should refine this understanding and further assist the teaching and learning of literacy skills. Future research might attempt to investigate the separate roles of arm and whole body movements in this visuo-motor approach. Research might also examine the importance of varying letter size in these gross motor tracings, since variability is known to improve performance in different kinds of motor learning (Schmidt \& Lee, 2005). Finally, further evaluating the action-perception link in learning appears to be a highly worthwhile direction for both theoretical and practical research. At the theoretical level, it may shed light on which kinds of movement can improve learning, and, practically, there can be value in better understanding what currently practiced multisensory instruction may be most effective for what specific learning activities. 


\section{References}

Alamargot, D., Chesnet, D., Dansac, C., \& Ros, C. (2006). Eye and Pen: A new device to study reading during writing. Behaviour Research Methods, Instruments and Computers, 38(2), 287-299.

Amundson, S. J., \& Weil, M. (2001). Prewriting and handwriting skills. In J. Case-Smith, A. S. Allen, \& P. Nuse Pratt (Eds.), Occupational therapy for children (pp. 545-566) St. Louis, MO: C.V. Mosby.

Bara, F., \& Gentaz, E. (2011). Haptics in teaching handwriting: The role of perceptual and visuo-motor skills. Human Movement Science, 30, 745-759.

Bara, F., Gentaz, E., \& Colé, P. (2007). Haptics in learning to read with children coming from low socio-economic status families. British Journal of Developmental Psychology, 25, 643-663.

Bara, F., Gentaz, E., Colé, P., \& Sprenger-Charolles, L. (2004). The visuo-haptic and haptic exploration of letters increases the kindergarten-children's reading acquisition. Cognitive Development, 19, 433-449.

Baron I.S. (2000). Clinical implications and practical applications of child neuropsychological evaluations. In: Yeates K.O., Ris M.D., \& Taylor H.G. (Eds). Pediatric Neuropsychology: Research, theory and practice (pp.439-456). New York: Guilford Publications.

Barsalou, L. W. (2008). Grounded cognition. The Annual Review of Psychology, 59, 617-645.

Beebe D.W., Ris M.D., Brown T.M., \& Dietrich K.N. (2004). Executive functioning and memory for the Rey-Osterreith complex figure task among community adolescents. Applied Neuropsychology, 11, 91-98 
Blank, R., Smits-Engelsman, B., Polatajko, H., \& Wilson, P. (2012). European Academy for Childhood Disability (EACD): Recommendations on the definition, diagnosis and intervention of developmental coordination disorder (long version). Developmental Medicine \& Child Neurology, 54, 54-93. DOI:10.1111/j.1469-8749.2011.04171.

Chao, L. L., \& Martin, A. (2000). Representation of manipulable man-made objects in the dorsal stream. NeuroImage, 12, 478-484.

Chartrel, E., \& Vinter, A. (2008). The impact of spatio-temporal constraints on cursive letter handwriting in children. Learning and Instruction, 18(6), 537-547

Connor, C. M., Morrisson, F. J., \& Slominski, L. (2006). Preschool instruction and children's emergent literacy growth. Journal of Educational Psychology, 98(4), 665-689.

Cornhill, H., \& Case-Smith, J. (1996). Factors that relate to good and poor handwriting. American Journal of Occupational Therapy, 50, 732-739.

Cratty, B. J. (1979). Perceptual and motor development in infants and children. Englewood Cliffs, NJ: Prentice-Hall.

Danna, J., \& Velay, J. L. (2015). Basic and supplementary sensory feedback in handwriting. Frontiers in Psychology, 6:169. DOI : 10.3389/fpsyg.2015.00169.

Daly, C. J., Kelley, G. T., \& Krauss, A. (2003). Relationship between visual-motor integration and handwriting skills of children in kindergarten: A modified replication study. American Journal of Occupational Therapy, 57, 459-462.

Ehri, L. C., Nunes, S. R., Willows, D. M., Schuster, D. M., Yaghoub-Zadeh, Z., \& Shanahan, T. (2001). Phonemic awareness instruction helps children learn to read: Evidence from the National Reading Panel's meta-analysis. Reading Research Quarterly, 36, 250-287.

Ehri, L. C., \& Sweet, J. (1991). Finger-point reading of memorized text: What enables beginners to process the print? Reading Research Quarterly, 26, 442-462.

Evans, M. A., Bell, M., Shaw, D., Moretti, M., \& Page, J. (2006). Letter names, letter sounds 
and phonological awareness: An examination of kindergarten children across letters and letters across children. Reading and Writing, 19, 959-989.

Foulin, J.-N. (2005). Why is letter-name knowledge such a good predictor of learning to read? Reading and Writing, 18, 129-155.

Gentaz, E., Bara, F., Palluel-Germain, R., Pinet L., \& Hillairet de Boisferon, A. (2009). Apports de la modalité haptique manuelle dans les premiers apprentissages scolaires [Haptic modality in learning]. In Cognito-Cahiers Romans de Sciences Cognitives, $3(3), 1-38$.

Guinet, E., \& Kandel, S. (2010). Ductus: A software package for the study of handwriting production. Behavior Research Methods, 42(1), 326-332.

Hammill, D. D. (2004). What we know about correlates of reading. Exceptional Children, 70, 453-468.

Helbig, H. B., Graf, M., \& Kiefer, M. (2006). The role of action representations in visual object recognition. Experimental Brain Research, 174, 221-228.

Hoy, M.M.P., Egan, M.Y et Feder, K.P. (2011). A systematic review of interventions to improve handwriting. Canadian Journal of Occupational Therapy, 78, 13-25.

James, K. H., \& Atwood, T. P. (2009). The role of sensorimotor learning in the perception of letter-like forms: Tracking the causes of neural specialization for letters. Cognitive Neuropsychology, 26, 91-110.

James, K. H., \& Gauthier, I. (2006). Letter processing automatically recruits a sensory-motor brain network. Neuropsychologia, 44, 2937-2949.

Justice, L. M., Pence, K., Bowles, R. B., \& Wiggins, A. (2006). An investigation of four hypotheses concerning the order by which 4-year-old children learn the alphabet letters. Early Childhood Research Quarterly, 21, 374-389.

Kellogg, R. T. (2001). Competition for working memory among writing processes. American Journal of Psychology, 114, 175-191. 
Kiefer, M., \& Trumpp, N. M. (2012). Embodiment theory and education: The foundations of cognition in perception and action. Trends in Neuroscience and Education, 1, 15-20.

Kirkwood M., Weiler M.D., Berstein J.H., Forbes P.W., \& Waber D.P. (2001). Sources of poor performance on the Rey-Osterrieth Complex Figure Test among children with learning difficulties: A dynamic assessment approach. The Clinical Neuropsychologist, $15,345-356$.

Lambert, E., \& Espéret, E. (2002). Assemblage des unités traitées par les processus graphomoteurs et orthographiques lors de l'apprentissage de l'écriture [Unit chunking in graphomotor and orthographic processes in writing acquisition]. Revue de Psychologie de l'Education, 7, 76-97.

Labat, H., Ecalle, J., \& Magnan, A. (2010). Effet d'entraînements bimodaux à la connaissance des lettres. Etude transversale chez des enfants de trois à cinq ans. [Effect of dual-mode training in letter knowledge: A cross-sectional study with 3- and 5-year-old children]. Psychologie Française, 55, 113-127.

Longcamp, M., Anton, J. L., Roth, M., \& Velay, J.-L. (2003). Visual presentation of single letters activates a premotor area involved in writing. NeuroImage, 19, 1492-1500.

Longcamp, M., Zerbato-Poudou, M. T., \& Velay, J.-L. (2005). The influence of writing practice on letter recognition in preschool children: A comparison between handwriting and typing. Acta Psychologica, 119, 67-69.

Martin, A. (2007). The representation of object concepts in the brain. Annual Review of Psychology, 58, 25-45.

McPhillips, M., Hepper, P.G., \& Mulhem, G. (2000). Effects of replicating primary reflex movementson specific reading difficulties in children: A randomised, double blind, controlled trial. The Lancet, 355, 537-541.

Molfese, V. J., Beswick, J., Molnar, A., \& Jacobi-Vessels, J. (2006). Alphabetic skills in 
preschool: A preliminary study of letter naming and letter writing. Developmental Neuropsychology, 29(1), 5-19.

Niklasson, M. (2012). “Could motor development be an emergent property of vestibular stimulation and primary reflex inhibition? A tentative approach to sensorimotor therapy," in Learning Disabilities, ed. W. Sittiprapaporn (Rijeka: In Tech), 241-274.

Olive, T. (2012). Writing and working memory: A summary of theories and of findings. In E. Grigorenko, E. Mambrino, \& D. Preiss (Eds.), Handbook of writing: A mosaic of new perspectives. New York: Psychology Press.

Paz-Villagran, V., Danna, J., \& Velay, J.-L. (2014). Lifts and stops in proficient and dysgraphic handwriting. Human Movement Science, 33, 381-394.

Pennington, B. F., \& Lefly, D. L. (2001). Early reading development in children at risk for dyslexia. Child Development, 72, 816-833.

Piasta, S. B., Purpura, D. J., \& Wagner, R. K. (2010). Fostering alphabet knowledge development: A comparison of two instructional approaches. Reading and Writing, 23, 607-626.

Piasta, S. B., \& Wagner, R. K. (2010). Developing early literacy skills: A meta-analysis of alphabet learning and instruction. Reading Research Quarterly, 45(1), 8-38.

Pulvermüller, F. (2005). Brain mechanisms linking language and action. Nature Reviews Neuroscience, 6, 576-582.

Puranik, C. S., Al Otaiba, S., Sidler, J. F., \& Greulich, L. (2014). Exploring the amount and type of writing instruction during language arts instruction in kindergarten classrooms. Reading and writing, 27(2), 213-236.

Puranik, C., Lonigan, C. J., \& Kim, Y. S. (2011). Contributions of emergent literacy skills to name writing, letter writing, and spelling in preschool children. Early Childhood Research Quarterly, 26, 465-474. 
Puranik, C., Petscher, Y., \& Lonigan, C. J. (2014). Learning to write letters: Examination of student and letters factors. Journal of Experimental Child Psychology, 128, 152-170.

Raibert, M.H. (1977). Motor control and learning by the state-space model: Technical report. Cambridge MA: Artificial Intelligence Laboratory, Massachusetts Institute of Technology.

Rey, A. (1959). Manuel du test de copie et de reproduction de mémoire des figures géométriques complexes. Paris: ECPA.

Rosenblum, S. (2015). Do motor ability and handwriting kinematic measures predict organizational ability among children with Developmental Coordination Disorders?. Human movement science, 43, 201-215.

Rosenblum, S., Weiss, P. L., \& Parush, S. (2003). Product and process evaluation of handwriting difficulties. Educational Psychology Review, 15, 41-81.

Schatschneider, C., Fletcher, J. M., Francis, D. J., Carlson, C. D., \& Foorman, B. R. (2004). Kindergarten prediction of reading skills: A longitudinal comparative analysis. Journal of Educational Psychology, 96, 265-282.

Schneck, C. M., \& Henderson, A. (1990). Descriptive analysis of the developmental progression of grip position for pencil and crayon control in nondysfunctional children. American Journal of Occupational Therapy, 44, 893-900.

Schwellnus, E., Cameron, D., \& Carnahan, H. (2012). Which to choose: Manuscript or cursive handwriting? A review of the literature. Journal of Occupational Therapy, Schools and Early Intervention, 5(3-4), 248-258.

Shatil, E., Share, D. L., \& Levin, I. (2000). On the contribution of kindergarten writing to grade 1 literacy: A longitudinal study in Hebrew. Applied Psycholinguistics, 21, 1-21.

Schmidt, R.A., \& Lee, T.D. (2005). Motor Learning: A Behavioral Emphasis. 4th ed. Champaign, IL: Human Kinetics. 
Treiman, R., Kessler, B., \& Bourassa, B. (2001). Children's own names influence their spelling. Applied Psycholinguistics, 22, 555-570.

Tseng, M.H. \& Chow, S.M.K. (2000). Perceptual-motor function of school-age children with slow handwriting speed. American Journal of Occupational Therapy, 54, 83-88.

Van Hoorn, J. F., Maathuis, C. G., Peters, L. H., \& Hadders-Algra, M.I. (2010). Handwriting, visuomotor integration, and neurological condition at school age. Developmental Medicine \& Child Neurology, 52(10), 941-947.

Vinter, A., \& Chartrel, E. (2009). Effects of different types of learning on handwriting movements in young children. Learning and Instruction, 1-11.

Woodward, S., \& Swinth, Y. (2002). Multisensory approach to handwriting remediation: Perception of school-based occupational therapists. American Journal of Occupational Therapy, 56, 305-312. 
